\title{
Impact of superselective intra-arterial and systemic chemoradiotherapy for gingival carcinoma; analysis of treatment outcomes and prognostic factors
}

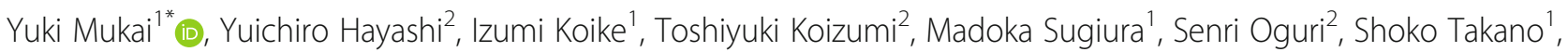
Mitomu Kioi ${ }^{2}$, Mizuki Sato' ${ }^{1}$ Kenji Mitsudo ${ }^{2}$ and Masaharu Hata ${ }^{1}$

\begin{abstract}
Background: We compared outcomes and toxicities between concurrent retrograde super-selective intra-arterial chemoradiotherapy (IACRT) and concurrent systemic chemoradiotherapy (SCRT) for gingival carcinoma (GC).

Methods: We included 84 consecutive patients who were treated for non-metastatic GC $\geq$ stage III, from 2006 to 2018, in this retrospective analysis (IACRT group: $n=66$; SCRT group: $n=18$ ).

Results: The median follow-up time was 24 (range: 1-124) months. The median prescribed dose was 60 (6-70.2) Gy (IACRT: 60 Gy; SCRT: 69 Gy). There were significant differences between the two groups in terms of 3-year overall survival (OS; IACRT: 78.8, 95\% confidence interval [CI]: 66.0-87.6; SCRT: 50.4, 95\% Cl: 27.6-73.0; $P=0.039$ ), progressionfree survival (PFS; IACRT: 75.6, 95\% Cl: 62.7-85.2; SCRT: 42.0, 95\% Cl: 17.7-70.9; $P=0.028$ ) and local control rates (LC; IACR T: 77.2, 95\% Cl: 64.2-86.4; SCRT: 42.0, 95\% Cl: 17.7-70.9; $P=0.015)$. In univariate analysis, age $\geq 65$ years, decreased performance status (PS) and SCRT were significantly associated with worse outcomes $(P<0.05)$. In multivariate analysis, age $\geq 65$ years, clinical stage IV, and SCRT were significantly correlated with a poor OS rate $(P<0.05)$. Patients with poorer PS had a significantly worse PFS rate. Regarding acute toxicity, 22 IACRT patients had grade 4 lymphopenia, and osteoradionecrosis was the most common late toxicity in both groups.
\end{abstract}

Conclusions: This is the first report to compare outcomes from IACRT and SCRT among patients with GC. ALL therapy related toxicities were manageable. IACRT is an effective and safe treatment for GC.

Keywords: Gingival carcinoma, Chemoradiotherapy, Superselective intra-arterial chemoradiotherapy, External beam radiation therapy, 3-dimensional radiation therapy

\footnotetext{
*Correspondence: y_mukai@yokohama-cu.ac.jp

'Departments of Radiation Oncology, Yokohama City University Graduate School of Medicine, 3-9 Fukuura, Kanazawa-ku, Yokohama 236-0004, Japan Full list of author information is available at the end of the article
}

C C The Author(s). 2020 Open Access This article is licensed under a Creative Commons Attribution 4.0 International License, which permits use, sharing, adaptation, distribution and reproduction in any medium or format, as long as you give appropriate credit to the original author(s) and the source, provide a link to the Creative Commons licence, and indicate if changes were made. The images or other third party material in this article are included in the article's Creative Commons licence, unless indicated otherwise in a credit line to the material. If material is not included in the article's Creative Commons licence and your intended use is not permitted by statutory regulation or exceeds the permitted use, you will need to obtain permission directly from the copyright holder. To view a copy of this licence, visit http://creativecommons.org/licenses/by/4.0/ The Creative Commons Public Domain Dedication waiver (http://creativecommons.org/publicdomain/zero/1.0/) applies to the data made available in this article, unless otherwise stated in a credit line to the data. 


\section{Background}

Oral cancers are the 6th most common malignancy, comprising $1-3 \%$ of all malignancies [1-7]. Gingival carcinoma (GC) represents $<10 \%$ of all oral cancers in Europe and the United States, compared with 15-20\% of oral cancers in Japan [1-7].

Surgical resection is the standard therapy for most oral cancers, especially early-stage disease, and is a wellestablished treatment for $\mathrm{GC}[2,8,9]$. Other treatment options for oral cancers include combinations of radiation therapy (RT) including external beam RT and brachytherapy, and chemotherapy, which are considered to be organ-preserving treatments $[1,6,8,10]$. Although brachytherapy is considered an effective organ-preserving treatment for oral cancers, particularly tongue cancer, it is often not indicated for GC because seed insertion may be challenging, and the risk of osteoradionecrosis is higher than for other oral cancers, because of the bone proximity. For unresectable cases, various chemoradiation therapies (CRT) are used, including super-selective intra-atrial, intravenous, or oral chemotherapy delivery. Intra-arterial chemoradiotherapy (IACRT) is effective for primary tumors, but might be inappropriate for distant metastases $[10,11]$. However, IACRT is an effective treatment option for patients with locally advance disease without distant metastasis, patients requiring organ-preserving treatments, cases that are not suitable for brachytherapy, and for unresectable cases such as patients with advanced primary tumors or comorbidities.

Although we previously investigated the outcomes of concurrent retrograde super-selective IACRT for GC [1], few studies have summarized the use of CRT for only GC and the optimal means of administering chemotherapy in this setting is unclear. This analysis therefore compared outcomes and toxicities between patients treated with concurrent retrograde super-selective IACR $\mathrm{T}$ and concurrent systemic chemoradiotherapy (SCRT) for $\mathrm{GC}$, based on patients from a previous study [1].

\section{Methods}

Patients

A total of 103 patients with GC and no distant metastasis underwent RT with curative intent at our institution between August 2006 and August 2018, of whom 84 were diagnosed as stage III or more advanced disease and were eligible for this study. The eligibility criteria were patients who received IACRT or SCRT with curative intent at our institution from 2006 to 2018, who did not receive initial surgery for the following reasons: some were considered unresectable because of primary tumor invasion; some patients with early-stage disease preferred/selected organ-preserving treatment over surgery; and some patients were unsuitable for surgery because of comorbidities, poor performance status (PS) and/or old age. Of these 84 patients, 66 received concurrent retrograde super-selective IACRT (IACRT group) and 18 received SCRT (SCRT group).

We retrospectively reviewed patients' medical records. Clinical staging was determined by physical examination, chest X-ray, ultrasound examinations, head-pelvis computed tomography (CT), cervical magnetic resonance imaging (MRI), and positron emission tomography (PET)-CT. All patients were examined before treatment and were classified according to the International Union Against Cancer staging system and categorized according to the National Comprehensive Cancer Network (NCCN) risk classification criteria (TNM Classification of Malignant Tumors, 8th edition).

The disease characteristics of the 84 patients are summarized in Table 1. All patients were histopathologically diagnosed by biopsy of the gingiva. This study was approved by Yokohama City University Certified Institutional Review Board (B190800011, date of registration 21/10/2019), and informed consent was obtained from all patients prior to treatment. All methods were performed in accordance with the relevant guidelines and regulations.

\section{Treatment}

According to our previously published study [1], patients received external irradiation at a planned total dose of 60-70 Gy in 30-35 fractions using three-dimensional RT. The fraction size was 2 Gy delivered daily, 5 days per week, using $6 \mathrm{MV}$ X-rays and a shrinking field technique. Gross tumor volume (GTV) was defined as the primary tumor and the metastatic lymph nodes, the clinical target volume (CTV) was defined as GTV plus 5 $\mathrm{mm}$ margins, and the planning target volume was defined as CTV plus 5-10 mm margins.

In patients with no cervical lymph node metastasis and T2-4 primary tumors, the radiation field was set up to include the primary tumors and prophylactically the ipsilateral cervical lymph node area (levels I-III). Patients with cervical lymph node metastasis underwent irradiation of the primary tumors and the ipsilateral (levels I-IV for N1) or bilateral (levels I-V for $\geq$ N2) cervical lymph node area, including metastatic lymph nodes. After a total dose of $40 \mathrm{~Gy}$ had been delivered to the initial field, an additional 20-30 Gy was delivered to the GTV within the shrunken field. Prophylactic cervical irradiation was delivered in $40 \mathrm{~Gy}$ doses. The total dose to the spinal cord was restricted to $45 \mathrm{~Gy}$ in all patients. An example of contouring and dose distribution is shown in Fig. 1.

\section{Chemotherapy}

In the IACRT group, catheters were placed via the superficial temporal artery and occipital artery and CT 
Table 1 Patient characteristics

\begin{tabular}{|c|c|c|c|}
\hline $\mathbf{N}$ & IACRT group & SCRT group & $P$ value \\
\hline The number of patients & $66(100 \%)$ & $18(100 \%)$ & \\
\hline \multicolumn{4}{|l|}{ Age, years } \\
\hline Median & 73 (range, 46-93) & 70.5 (range, 51-91) & $\begin{array}{l}0.26 \\
(<65 \text { years })\end{array}$ \\
\hline \multicolumn{4}{|l|}{ Gender } \\
\hline Male & $32(48.5 \%)$ & $14(77.8 \%)$ & 0.18 \\
\hline Female & $34(51.5 \%)$ & $4(22.2 \%)$ & \\
\hline \multicolumn{4}{|l|}{ ECOG PS } \\
\hline 0 & $50(75.8 \%)$ & $10(55.6 \%)$ & 0.050 \\
\hline 1 & $16(24.2 \%)$ & $7(38.8 \%)$ & \\
\hline 2 & 0 & $1(5.6 \%)$ & \\
\hline \multicolumn{4}{|l|}{ Histology } \\
\hline Squamous cell carcinoma & $63(95.5 \%)$ & $17(94.4 \%)$ & NA \\
\hline Verrucous carcinoma & $1(1.5 \%)$ & $1(5.6 \%)$ & \\
\hline Poorly differentiated carcinoma & $2(3 \%)$ & 0 & \\
\hline \multicolumn{4}{|c|}{ Clinical stage (TNM Classification of Malignant Tumors, 8th edition) } \\
\hline Stage III & $14(21.2 \%)$ & $3(16.7 \%)$ & 0.68 \\
\hline Stage IVA & $49(74.3 \%)$ & $13(72.2 \%)$ & \\
\hline Stage IVB & $3(4.5 \%)$ & $2(11.1 \%)$ & \\
\hline T category & & & 0.27 \\
\hline $\mathrm{T} 2$ & $7(10.6 \%)$ & $2(11.1 \%)$ & \\
\hline T3 & $17(25.8 \%)$ & $2(11.1 \%)$ & \\
\hline T4a & $37(56.0 \%)$ & $11(61.1 \%)$ & \\
\hline T4b & $5(7.6 \%)$ & $3(16.7 \%)$ & \\
\hline N category & & & 0.22 \\
\hline NO & 25 (37.9\%) & $4(22.2 \%)$ & \\
\hline N1 & $12(18.2 \%)$ & $4(22.2 \%)$ & \\
\hline $\mathrm{N} 2 \mathrm{a}$ & 0 & $1(5.6 \%)$ & \\
\hline $\mathrm{N} 2 \mathrm{~b}$ & 22 (33.3\%) & $3(16.7 \%)$ & \\
\hline $\mathrm{N} 2 \mathrm{C}$ & $5(7.6 \%)$ & $6(33.3 \%)$ & \\
\hline N3a & $2(3 \%)$ & 0 & \\
\hline \multicolumn{4}{|l|}{ Location } \\
\hline$L t$ & 35 (53.0\%) & $12(66.7 \%)$ & 0.34 \\
\hline Rt & 25 (37.9\%) & $5(27.7 \%)$ & \\
\hline Middle & $6(9.1 \%)$ & $1(5.6 \%)$ & \\
\hline Upper/maxillary & $41(62.1 \%)$ & $7(38.8 \%)$ & 0.19 \\
\hline Lower/mandibular & 25 (37.9\%) & $11(61.2 \%)$ & \\
\hline $\begin{array}{l}\text { Tumor diameter } \\
\text { (maximum, mm) }\end{array}$ & 40 (range, 12-60) & 45 (range, 20-90) & 0.31 \\
\hline
\end{tabular}

Comparison of clinical variables between the two groups was performed using Mann-Whitney's U-test EOCG PS Eastern Cooperative Oncology Group performance status

angiography with indigo-carmine injection was initially performed to detect tumor-feeding arteries and details of tumor invasion. Primary tumors are often fed by maxillary artery and facial artery. In cases where the mandibular gingival tumor had spread to the lingual side or the mouth floor, the lingual artery was catheterized. Chemotherapy was started at the same time as RT. The most frequently chemotherapy regimen was that 


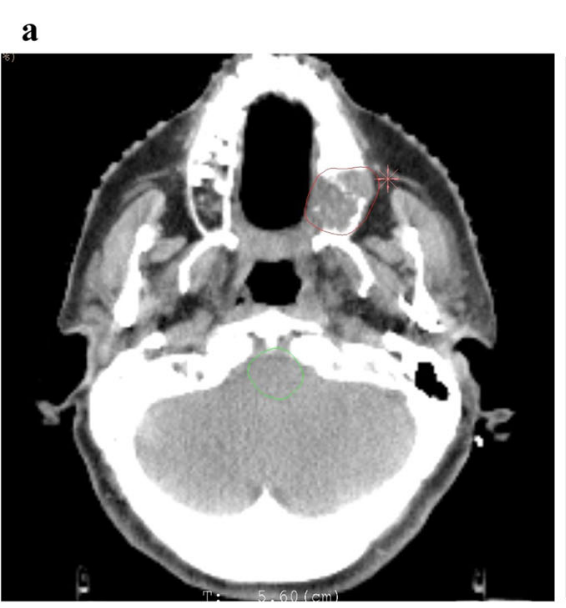

\section{b}

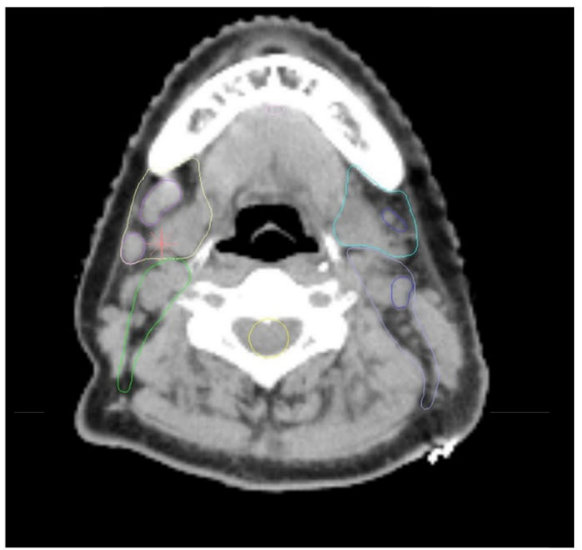

c

d

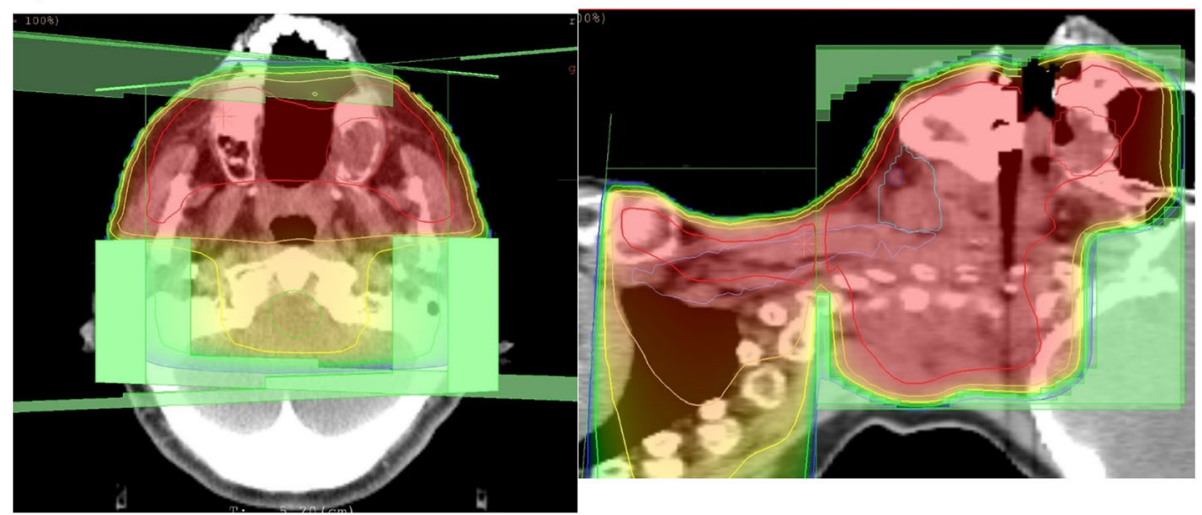

Fig. 1 Contouring of (a) primary tumor and (b) lymph node areas. (c, d) Dose distribution. Red lines indicate 100\% of prescription dose, orange $85 \%$, yellow $70 \%$, green $55 \%$, and blue $40 \%$

cisplatin $\left(5 \mathrm{mg} / \mathrm{m}^{2} /\right.$ day) and docetaxel (DOC; $10 \mathrm{mg} / \mathrm{m}^{2} /$ week) administered by infusion over a period of $1 \mathrm{~h}, 5$ days per week as a single course, for 6 weeks. Patients who received IACRT had no history of cerebral infarction; liver, kidney or heart dysfunction, or severe diabetes mellitus. In the SCRT group, 18 patients had chemotherapy with RT consisting of tegafur/gimeracil/ oteracil potassium (TS-1, 80-120 mg/day, $n=9$ ), cetuxi$\mathrm{mab}\left(250-400 \mathrm{mg} / \mathrm{m}^{2}, n=6\right)$, tegafur-uracil (UFT; 300 $\left.\mathrm{mg} / \mathrm{m}^{2}, n=2\right)$, or DOC $\left(60 \mathrm{mg} / \mathrm{m}^{2}\right)+$ fluorouracil $(100$ mg; $n=1$ ). The period of initial chemotherapy, in the SCRT group was the same as that of RT.

\section{Evaluation criteria and statistical analysis}

Responses were evaluated using clinical examination and CT, MRI and PET-CT studies at approximately 4-6 weeks after completing treatment. Tumor responses were assessed using Response Evaluation Criteria in Solid Tumors (ver. 1.1) [12]. If residual metastatic lymph nodes were suspected after treatment, radical neck dissection was planned. Toxicities associated with treatments were evaluated using the Common Terminology
Criteria for Adverse Events, v4.03 [13]. Acute toxicities were defined as therapy-related adverse events that occurred within 3 months after starting treatment, and late toxicities as those occurring after 3 months.

We compared clinical variables between the two groups using the Mann-Whitney U-test. Overall survival (OS), local control (LC), and progression-free survival (PFS) rates from the beginning of treatment were calculated with Kaplan-Meier curves. Differences between curves were tested by the log-rank test. Analyses of prognostic factors was carried out using univariate and multivariate Cox proportional-hazards regression models, with the Statistical Package for the Social Sciences (SPSS for Windows, version 23.0; IBM, Armonk, NY, USA). $P<0.05$ was considered significant.

\section{Results}

Treatment

The median follow-up time was 24 (range, 1-124) months in all patients. Treatment characteristics of the study group are summarized in Table 2 .The reasons for patients not receiving IACRT included the following: 
Table 2 Treatment related characteristics

\begin{tabular}{|c|c|c|c|}
\hline $\mathrm{N}$ & IACRT group & SCRT group & $P$ value \\
\hline Overall treatment time for radiation therapy (month) & 46.5 (range,8-73) & 52 (range,2-94) & 0.090 \\
\hline Total radiation dose (Gy) & 60 (range, 14-70.2) & 69 (range, 6-70.2) & 0.013 \\
\hline Radiation dose for prophylactic cervical LN node area (Gy) & 40 (range, 20-41.4) & 40 (range, 6-40) & 0.65 \\
\hline $\begin{array}{l}\text { RT field } \\
\text { Ipsilateral cervical LN area } \\
\text { Bilatera cervical LN area } \\
\text { Only primary tumor }\end{array}$ & $\begin{array}{l}\text { Ipsilateral: } 17(25.8 \%) \\
\text { Bilateral: } 45(68.2 \%) \\
\text { Primary tumor: } 4(6.0 \%)\end{array}$ & $\begin{array}{l}\text { Ipsilateral: } 3(16.6 \%) \\
\text { Bilateral: } 14 \text { (77.8\%) } \\
\text { Primary tumor: } 1(5.6 \%)\end{array}$ & 0.59 \\
\hline Chemotherapy & $\begin{array}{l}\text { CCDP+DOC: } 61(92.5 \%) \\
\text { CDDP+5FU: } 1 \text { (1.5\%) } \\
\text { CDDP+DOC+cetuximab:2 (3.0\%) } \\
\text { CDDP only: } 1 \text { (1.5\%) } \\
\text { CDDP+ cetuximab: } 1 \text { (1.5\%) }\end{array}$ & $\begin{array}{l}\text { TS-1: } 9(50 \%) \\
\text { UFT:2 (11.1\%) } \\
\text { DOC+5FU: } 1(5.6 \%) \\
\text { Cetuximab: } 6 \text { (33.3\%) }\end{array}$ & NA \\
\hline Gastrostomy & $\begin{array}{l}36 \text { (54.5\%) } \\
\text { Gastric tub: } 13 \text { (19.7\%) } \\
\text { Ingestion/oral intake17 (25.8\%) }\end{array}$ & $\begin{array}{l}4 \text { (22.2\%) } \\
\text { Gastric tub: } 3 \text { (16.7\%) } \\
\text { Ingestion/oral intake:11 (61.1\%) }\end{array}$ & 0.005 \\
\hline
\end{tabular}

Comparison of clinical variables between the two groups was performed using Mann-Whitney's U-test

$R T$ radiation therapy, $L N$ lymph node, CCDP cisplatin, DOC docetaxel, NA not applicable

difficulty in using contrast medium because of renal or liver dysfunction or allergy $(n=4)$; difficulty in placing/ inserting catheters because of dementia or anticoagulant use $(n=7)$; and advantage or preferability of systemic chemotherapy because of comorbidities (e.g., history of another carcinoma or tuberculosis, $n=6$ ). One patient switched to systemic chemotherapy because she had a stroke after catheter placement. The completion rates for IACRT and SCRT were 90.9 and $88.9 \%$, respectively. Six IACRT patients (9.1\%) and two SCRT patients (11.1\%) discontinued RT because of complications/coexisting disease (including infection, bleeding from gastrostomy, or delirium) or at the patient's request.

\section{Tumor control}

Following initial therapy, 14 patients in the IACRT group and 10 in the SCRT group had residual disease within the RT field. In the IACRT group, 10 patients with residual primary tumors received salvage therapy, which resulted in control in three. Salvage therapy included surgery for primary tumors or neck dissection $(n=3)$, additional RT (e.g., stereotactic body radiation therapy, $n=4)$ and additional chemotherapy $(n=3)$. In the SCRT group, four patients received salvage therapy, but none achieved disease control.

Among IACRT patients whose primary tumors were considered to be controlled, four patients underwent neck lymph node dissections, and three of these four patients had no evidence of malignancy in their neck lymph nodes. The 3-year LC rate differed significantly between the IACRT group (77.2\%; 95\% confidence interval $[C I]: 64.3-86.4)$ and the SCRT group (42.0\%; 95\% CI: 17.7-70.9) $(P=0.015)$ (Fig. 2a).

Regarding recurrence, 10 patients in the IACRT group and one in the SCRT group developed recurrence within the RT field, and eight patients in the IACRT group and four in the SCRT group had distant metastases. Seven IACRT patients (10.6\%) developed primary tumor recurrences, compared with no SCRT patients. Five IACRT patients $(7.6 \%)$ developed cervical lymph node recurrences compared with only one SCRT patient (5.6\%). Eight IACR $\mathrm{T}$ patients (12.1\%) experienced distant metastases (lung metastases with or without other sites: $n=6$, pleural dissemination or subcutaneous metastasis: $n=2$ ) compared with four SCRT patients (22.2\%; lung metastases: $n=3$, liver metastases: $n=1$ ). The lung metastasis rates in the IACRT and SCRT groups were 9.1 and 16.7\%, respectively. Four IACRT patients who received salvage therapy after recurrence were alive at the last follow-up.

\section{Survival}

The two groups differed significantly in terms of 3-year OS (IACRT: 78.8, 95\% CI: 66.0-87.6; SCRT: 50.4, 95\% CI: 27.6-73.0; $P=0.039$ ) and PFS rates (IACRT: 75.7, 95\% CI: 62.7-85.2; SCRT: 42.0, 95\% CI: 17.7-70.9; $P=$ 0.028) (Fig. $2 \mathrm{~b}$ and c). Among the 66 IACRT patients, 47 patients were alive, and 43 were considered achieved CR (median survival: 46 months, range: $7-124$ months) at May 31, 2019. Of the 19 IACRT patients who died within 1-56 months after treatment, 16 died of cancer and three died of non-cancer-related causes. In the SCRT group, only four had CR (median follow-up time: 84.5 months, range: $50-94$ months). Nine patients died (6 of cancer and 3 of non-cancer-related causes) and five patients changed hospital to receive palliative care. Neither group had any therapy-related mortality.

\section{Analysis of prognostic factors}

Univariate and multivariate analyses of factors associated with OS, PFS and LC rates are summarized in Tables 3 

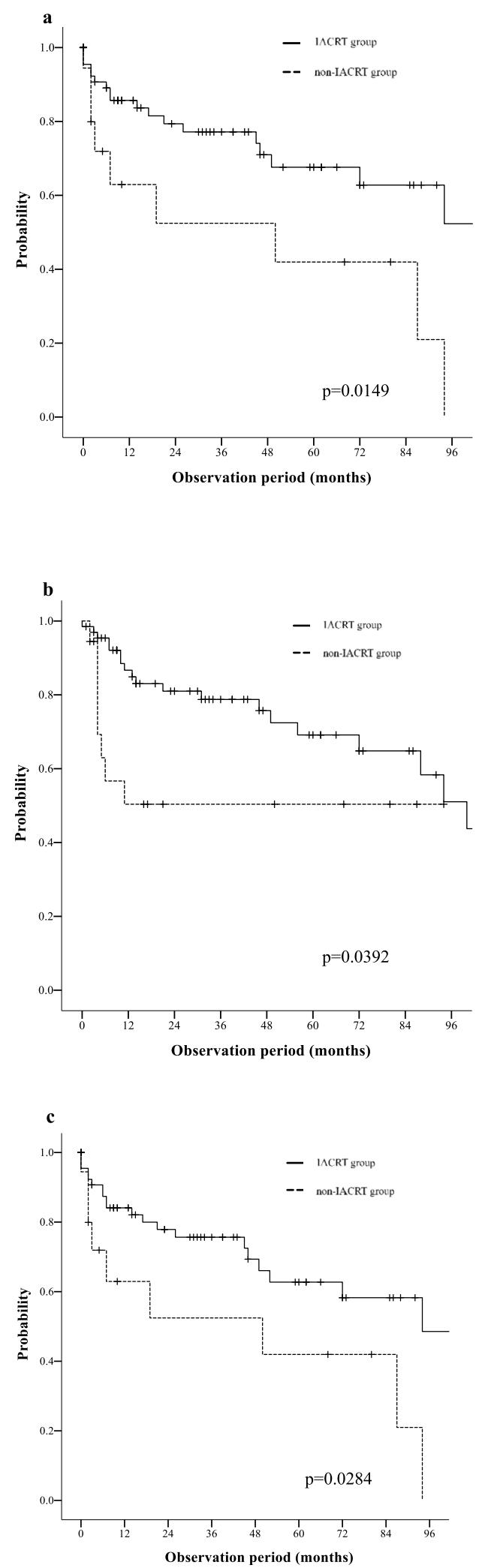

Fig. 2 a. Local control. b. Overall survival. c. Progression-free survival and 4. In univariate analysis, 65 years or older of age, poorer PS, and SCRT treatment were significantly associated with worse $\mathrm{OS}$ rate $(P=0.003, P=0.024, P=$ 0.047 , respectively). Among patients aged 65 years or older, clinical stage IV, > T3, > N2b, and SCRT treatment were significantly associated with worse PFS and worse LC rates $(P=0.033, P=0.029, P=0.041, P=0.004$, $P=0.048$, respectively). A prescribed dose $>60$ Gy was significantly associated with a worse PFS rate $(P=0.038)$.

In multivariate analysis, 65 years or older of age, clinical stage IV, and SCRT group were significantly correlated with poor OS rates $(P=0.022, P=0.009, P=0.041$, respectively). Patients with poorer PS had significantly worse PFS rate $(P=0.032)$.

\section{Toxicities}

Therapy-related acute toxicities are shown in Table 5 . The two groups differed significantly in the incidences of grade 3 leukopenia $(P=0.012)$, radiation dermatitis $(P=0.034)$, and dysphagia $(P=0.008)$. Interestingly, 22 IACRT patients had grade 4 lymphopenia, but recovered immediately after treatment. In both groups, osteoradionecrosis (mandibular: $n=13$; maxillary: $n=2$ ) was the most common late toxicity, affecting nine IACRT patients (13.6\%; median: 32 months; range: 17-107 months) and six SCRT patients (33.3\%; median 43 months; range: $3-16$ months $)(P=0.081)$. One IACRT patient developed a pharyngeal fistula and required surgery (grade 4). No SCRT patient developed any other late severe ( $\geq$ grade 3 ) toxicity associated with treatment.

\section{Discussion}

Surgery remains the standard curative treatment for oral cancer [1]. However, gingival tumors are often adjacent to the maxillary or mandibular bone, and mandibulectomy or maxillectomy may be required to secure adequate margins [14-17]. Patients with GC may thus suffer diminished quality of life after surgery, caused by oral dysfunction and cosmetic impairment. To the best of knowledge, this is the first study to compare intra-arterial chemoradiotherapy, and systemic chemoradiotherapy for GC. Although RT with intravenous or intra-arterial chemotherapy has previously been reported as an organ-preserving treatment for advanced oral carcinoma [1, 3], there are currently no prospective studies or established evidence for the use of these treatments for GC.

Lubek et al. reported that a cohort with GC (of whom half had stage I-II disease) treated with surgery alone had a 5-year OS rate of 38\% [4], while patients with lower/mandibular GC treated by surgery alone had 5year cause-specific and disease-specific survival rates of 73 and $80.6 \%$, respectively $[3,18,19]$. Among patients who received postoperative $\mathrm{RT}$ for $\mathrm{GC}$, including stage I-IV disease, the reported 5-year OS and disease-free 
Table 3 Univariate analysis for prognostic factors

\begin{tabular}{|c|c|c|c|c|c|c|c|c|c|c|}
\hline \multirow[t]{2}{*}{ Variables } & & \multicolumn{3}{|l|}{ os } & \multicolumn{3}{|l|}{ PFS } & \multicolumn{3}{|l|}{ LC } \\
\hline & & HR & $95 \% \mathrm{Cl}$ & $P$ value & $\mathrm{HR}$ & $95 \% \mathrm{Cl}$ & $P$ value & HR & $95 \% \mathrm{Cl}$ & $P$ value \\
\hline \multirow[t]{2}{*}{ Age, years } & $<65$ & $1 /$ reference & & & 1 & & & 1 & & \\
\hline & $\geq 65$ & 4.655 & 1.389-15.59 & 0.003 & 2.618 & $0.992-6.906$ & 0.033 & 3.1035 & $1.067-9.028$ & 0.019 \\
\hline \multirow[t]{2}{*}{ Gender } & Female & 1 & & & 1 & & & 1 & & \\
\hline & Male & 2.021 & $0.906-4.505$ & 0.076 & 1.312 & $0.630-2.733$ & 0.466 & 1.324 & $0.618-2.833$ & 0.468 \\
\hline \multirow[t]{2}{*}{ ECOG PS } & 0 & 1 & & & 1 & & & 1 & & \\
\hline & $>1$ & 2.555 & $1.168-5.589$ & 0.024 & 2.013 & $0.925-4.382$ & 0.091 & 1.893 & $0.8399-4.265$ & 0.139 \\
\hline \multirow[t]{2}{*}{ Clinical stage } & $\leq$ stage 3 & 1 & & & 1 & & & 1 & & \\
\hline & > stage 4 & 2.583 & $0.874-7.632$ & 0.058 & 2.905 & $0.994-8.490$ & 0.029 & 3.715 & $1.099-12.56$ & 0.014 \\
\hline \multirow[t]{2}{*}{ T category } & $\leq \mathrm{T} 3$ & 1 & & & 1 & & & 1 & & \\
\hline & $>\mathrm{T} 3$ & 1.204 & $0.548-2.649$ & 0.642 & 2.316 & $0.984-5.453$ & 0.041 & 2.567 & $1.0298-6.399$ & 0.029 \\
\hline \multirow[t]{2}{*}{ N category } & $\leq \mathrm{N} 2 \mathrm{~b}$ & 1 & & & 1 & & & 1 & & \\
\hline & $>\mathrm{N} 2 \mathrm{~b}$ & 2.794 & $1.077-7.252$ & 0.052 & 4.117 & $1.722-9.845$ & 0.004 & 4.430 & $1.831-10.72$ & 0.003 \\
\hline \multirow[t]{2}{*}{ Location } & Lower & 1 & & & 1 & & & 1 & & \\
\hline & Upper & 0.909 & $0.423-1.950$ & 0.806 & 0.796 & $0.382-1.658$ & 0.542 & 0.7923 & $0.370-1.695$ & 0.548 \\
\hline \multirow[t]{2}{*}{ Chemotherapy } & IACRT & 1 & & & 1 & & & 1 & & \\
\hline & SCRT & 2.34 & $1.012-5.41$ & 0.047 & 2.334 & $1.058-5.149$ & 0.048 & 2.586 & $1.156-5.786$ & 0.030 \\
\hline \multirow[t]{2}{*}{ RT field } & primary tumor & 1 & & & 1 & & & 1 & & \\
\hline & cervical LN area & 0.727 & $0.171-3.098$ & 0.680 & 1.492 & $0.348-6.390$ & 0.6099 & 1.591 & $0.369-6.858$ & 0.558 \\
\hline \multirow[t]{2}{*}{ Prescribed total dose } & $\leq 60 \mathrm{~Gy}$ & 1 & & & 1 & & & 1 & & \\
\hline & $>60$ Gy & 1.003 & $0.438-2.299$ & 0.993 & 2.225 & $1.066-4.65$ & 0.0378 & 2.177 & $1.015-4.672$ & 0.0515 \\
\hline
\end{tabular}

Table 4 Multivariate analysis for prognostic factors

\begin{tabular}{|c|c|c|c|c|c|c|c|c|c|c|}
\hline \multirow[t]{2}{*}{ Variables } & & \multicolumn{3}{|l|}{ os } & \multicolumn{3}{|l|}{ PFS } & \multicolumn{3}{|l|}{ LC } \\
\hline & & HR & $95 \% \mathrm{Cl}$ & $P$ value & $\overline{H R}$ & $95 \% \mathrm{Cl}$ & $P$ value & HR & $95 \% \mathrm{Cl}$ & $P$ value \\
\hline \multirow[t]{2}{*}{ Age, years } & $<65$ & 1 & & & 1 & & & 1 & & \\
\hline & $\geq 65$ & 3.645 & $1.041-12.77$ & 0.022 & 1.835 & $0.671-5.015$ & 0.212 & 2.210 & $0.732-6.675$ & 0.130 \\
\hline \multirow[t]{2}{*}{ ECOG PS } & 0 & 1 & & & 1 & & & 1 & & \\
\hline & $>1$ & 1.956 & $0.807-4.738$ & 0.144 & 2.865 & $1.125-7.298$ & 0.032 & 2.521 & $0.935-6.801$ & 0.074 \\
\hline \multirow[t]{2}{*}{ Clinical stage } & $\leq$ stage 3 & 1 & & & 1 & & & 1 & & \\
\hline & $>$ stage 4 & 6.735 & $1.581-28.70$ & 0.009 & 1.866 & $0.368-.465$ & 0.459 & 2.609 & $0.462-14.73$ & 0.284 \\
\hline \multirow[t]{2}{*}{ T category } & $\leq \mathrm{T} 3$ & 1 & & & 1 & & & 1 & & \\
\hline & $>\mathrm{T} 3$ & 1.921 & $0.677-5.469$ & 0.236 & 1.618 & $0.452-.785$ & 0.437 & 1.513 & $0.417-5.480$ & 0.512 \\
\hline \multirow[t]{2}{*}{ N category } & $\leq \mathrm{N} 2 \mathrm{~b}$ & 1 & & & 1 & & & 1 & & \\
\hline & $>\mathrm{N} 2 \mathrm{~b}$ & 1.425 & $0.513-3.957$ & 0.506 & 2.468 & $0.966-6.301$ & 0.069 & 2.415 & $0.936-6.229$ & 0.078 \\
\hline \multirow[t]{2}{*}{ Chemotherapy } & IACRT & 1 & & & 1 & & & 1 & & \\
\hline & SCRT & 3.161 & $1.055-9.468$ & 0.041 & 1.389 & $0.524-3.686$ & 0.511 & 1.630 & $0.595-4.463$ & 0.344 \\
\hline \multirow[t]{2}{*}{ Prescribed total dose } & $\leq 60 \mathrm{~Gy}$ & 1 & & & 1 & & & 1 & & \\
\hline & $>60 \mathrm{~Gy}$ & 1.992 & $0.718-5.533$ & 0.174 & 1.715 & $0.674-4.359$ & 0.262 & 1.438 & $0.543-3.808$ & 0.468 \\
\hline
\end{tabular}


Table 5 Acute toxicity

\begin{tabular}{|c|c|c|c|c|c|c|c|c|c|}
\hline \multirow[t]{2}{*}{ Acute Toxicities } & \multicolumn{4}{|c|}{ IACRT group } & \multicolumn{4}{|c|}{ SCRT group } & \multirow{2}{*}{$\begin{array}{l}P \text { value } \\
\geq \text { Grade } 3\end{array}$} \\
\hline & $\leq$ Grade 1 & Grade 2 & Grade 3 & $\geq$ Grade 4 & $\leq$ Grade 1 & Grade 2 & Grade 3 & $\geq$ Grade 4 & \\
\hline \multicolumn{10}{|l|}{ Hematologic toxicity } \\
\hline Anemia & $21(31.8 \%)$ & $35(53.1 \%)$ & $10(15.1 \%)$ & 0 & $6(33.3 \%)$ & $11(61.1 \%)$ & $1(5.6 \%)$ & 0 & 0.24 \\
\hline leukopenia & $23(34.8 \%)$ & 19 (28.8\%) & 19 (28.8\%) & $5(7.6 \%)$ & $14(77.7 \%)$ & $3(16.7 \%)$ & $1(5.6 \%)$ & 0 & 0.012 \\
\hline Neutropenia & 37 (56.1\%) & $15(22.7 \%)$ & $13(19.7 \%)$ & $1(1.5 \%)$ & 17 (94.4\%) & 0 & $1(5.6 \%)$ & 0 & 0.13 \\
\hline lymphopenia & $6(9.1 \%)$ & $12(18.2 \%)$ & $26(39.4 \%)$ & $22(33.3 \%)$ & $7(38.8 \%)$ & $1(5.6 \%)$ & $10(55.6 \%)$ & 0 & 0.21 \\
\hline thrombopenia & $61(92.5 \%)$ & $2(3.0 \%)$ & $3(4.5 \%)$ & 0 & $18(100 \%)$ & 0 & 0 & 0 & 0.37 \\
\hline \multicolumn{10}{|l|}{ General conditions } \\
\hline Radiation dermatitis & 25 (37.9\%) & 27 (40.9\%) & $12(18.2 \%)$ & $2(3.0 \%)$ & $8(\%)$ & $10(\%)$ & 0 & 0 & 0.034 \\
\hline Oral mucositis & $2(3.0 \%)$ & $20(30.3 \%)$ & $43(65.2 \%)$ & $1(1.5 \%)$ & $3(16.7 \%)$ & 7 (38.8\%) & 7 (38.8\%) & $1(5.6 \%)$ & 0.088 \\
\hline Xerostomia & $43(65.2 \%)$ & $20(30.3 \%)$ & $2(3.0 \%)$ & 0 & $10(55.6 \%)$ & $8(44.4 \%)$ & 0 & 0 & 0.46 \\
\hline Dysphagia & 0 & $17(25.8 \%)$ & $49(74.2 \%)$ & 0 & 0 & $11(61.1 \%)$ & 7 (38.8\%) & 0 & 0.008 \\
\hline
\end{tabular}

IACRT Intra-arterial chemoradiation, SCRT systemic chemoradiation therapy

survival rates were $36.5-95 \%$ and $21.1-68 \%$, respectively $[6,20]$. Lank et al. compared definitive RT and postoperative RT using intensity-modulated radiation therapy for stage III-IV GC and found a 5-year OS rate of 36.6\%; however, only $53.9 \%$ patients in their study received concurrent chemotherapy or immunotherapy [20].

In the current study, the 3-year OS, PFS and LC rates in the IARCT and SCRT groups were 78.8 and $50.4 \%$, 75.6 and $42.0 \%$, and 77.2 and $42.0 \%$, respectively. Comparisons with previous studies may be difficult because of their differing populations and stages. However, the overall outcome of the present study was comparable to or better than previous reports of surgery and postoperative RT $[3,4,6,18-20]$. Other reports on IACRTtreated oral cancers reported distant metastasis rates of $10-23 \%[10,11]$, whereas the rate in the present study was lower in the IACRT group (12.1\%) than in the SCRT group (22.2\%), and half of the patients who developed distant metastasis did not have controlled primary tumors. Furthermore, three of four (75\%) IACRT patients were pathologically confirmed to have no evidence of malignancy in their neck lymph nodes after lymph node dissection. IACRT may be disadvantageous with respect to distant or locoregional (lymph node) metastasis because this method distributes chemotherapy drugs to relatively limited areas. Our IACRT and SCRT groups showed significantly different in OS $(P=0.039)$, PFS $(P=0.028)$, and $\mathrm{LC}$ rates $(P=0.015)$ at 3 years. Moreover, in multivariate analysis, IACRT was significantly correlated with better OS rate $(P=0.041)$. These results suggest that intensive local therapy for primary tumors leads to better control of metastasis. The present study found that RT doses $>60$ Gy were significantly associated with worse PFS rates in univariate analysis. The median prescribed dose was higher in the SCRT group (69 Gy) than in the IACRT group (60 Gy) $(P=0.013)$. The
2019 NCCN guidelines recommended $66-70$ Gy as the definitive RT dose for cancer of the oral cavity; however, this is not a recommendation for IACRT. In our study, an additional dose $>60$ Gy was prescribed in cases with macroscopic residual tumor in the latter half of the RT; however, dose-escalation $>60$ Gy may be not effective in IACRT in these cases. This may account for the apparent discrepancy with the international treatment guidelines.

Among therapy-related acute toxicities, $\geq$ grade 3 leukopenia, radiation dermatitis, and dysphagia rates were higher in the IACRT group than in the SCRT group. However, they were all transient and the completion rate was almost $90 \%$ for both treatments. Watanabe et al. compared osteoradionecrosis rates between intravenous CRT and IACRT in various oral cancers, including a few GCs, and reported a higher, but not significant, incidence in the IACRT group (CRT 10\%; IACRT 17\%) [21]. They suggested that prophylactic dental care is effective against radiation-induced toxicity. We did not expect the osteoradionecrosis rate to be lower in the IACRT group (13.6\%) compared with the SCRT group $(33.3 \%)(P=0.081)$, because we previously found the opposite situation [1]. We suppose that oral hygiene for the IACRT patients in our study may have been carefully managed, which may have led to the lower osteoradionecrosis rate in the IACRT group.

One patient developed a stroke after catheter placement. Her only complication at that time was hypertension, and the direct cause of her stroke was unclear. Eight patients terminated RT, mostly because of infection (catheter or enteritis) (37.5\%). Given that the IACR $\mathrm{T}$ group had a higher rate of leukopenia than the SCRT group, the risk of infection may also have been higher. Marta et al. reported that the GC patients with diabetes mellitus had a higher recurrence rate after postoperative 
RT [22]. Taken together, we suggest careful management of oral hygiene and infection monitoring during IACRT, and careful follow-up for patients with diabetes mellitus after treatment.

This study had several limitations, including its retrospective design, the much greater size of the IACRT group compared with the SCRT group, and the relatively short overall follow-up time. The reasons why patients did not receive IACRT are given in the Results section, but the selection of patients to receive IACRT or SCRT represents a major bias of this study. Moreover, patients with poorer PS had significantly different PFS rates in multivariate analysis $(P=0.032)$, and PS differed significantly between the two groups $(P=0.050)$; this should therefore be considered when interpreting our results.

\section{Conclusion}

IACRT led to significantly better 3-year outcomes than SCRT in patients with GC and was an independent predictor of better OS rates in multivariate analysis. IACRT is thus an effective and safe treatment for GC; however, further studies are needed to determine its long-term efficacy and late toxicities. Nevertheless, IACRT is an effective organ-preserving treatment choice for patients with GC.

\begin{abstract}
Abbreviations
GC: Gingival carcinoma; RT: Radiation therapy; CRT: Chemoradiation therapies; IACRT: Intra-arterial chemoradiation; SCRT: Systemic chemoradiation therapy; CT: Computed tomography; MRI: Magnetic resonance imaging; NCCN: National Comprehensive Cancer Network; GTV: Gross tumor volume; CTV: Clinical target volume; PTV: Planning target volume; RECIST: Response Evaluation Criteria in Solid Tumors; CTCAE: Common Terminology Criteria for Adverse Events; OS: Overall survival; LC: Local control; PFS: Progression-free survival; SPSS: Statistical Package for the Social Sciences; CR: Complete response; QOL: Quality of life; DFS: Disease-free survival; IMRT: Intensity-modulated radiation therapy
\end{abstract}

\section{Acknowledgements}

Not applicable.

\begin{abstract}
Authors' contributions
YM has made the design of the work, analyzed and interpreted data, and have drafted the work. She has performed a major contribution in writing the manuscript. MH made substantial contributions to the conception and substantively revised it. IK, MS, ST, and MS have made the acquisition, analysis of data and have substantively revised it. YH, TK, SO, MK, and KM have substantively revised it. All authors have approved the submitted version.
\end{abstract}

\section{Funding}

This study did not receive any specific grant from funding agencies in the public, commercial, or not-for-profit sectors.

\section{Availability of data and materials}

The datasets used and/or analysed during the current study are available from the corresponding author on reasonable request.

\section{Ethics approval and consent to participate}

The Institutional Review Board (IRB) of Yokohama City University approved this study. The ethical committee approval number is B190800011. Written informed consent of using patients' data was obtained before the treatment. Administrative permissions were acquired to access the clinical/personal patient data used in our research. The president of Yokohama City University Hospital provided administrative permissions for access to the data.
Consent for publication

Not Applicable.

\section{Competing interests}

The authors declare that they have no competing interests.

\section{Author details}

'Departments of Radiation Oncology, Yokohama City University Graduate School of Medicine, 3-9 Fukuura, Kanazawa-ku, Yokohama 236-0004, Japan. ${ }^{2}$ Departments of Oral and Maxillofacial Surgery Yokohama City University Graduate School of Medicine 3-9 Fukuura, Kanazawa-ku Yokohama 236-0004 Japan

Received: 7 August 2020 Accepted: 15 November 2020

Published online: 26 November 2020

\section{References}

1. Mukai Y, Hata M, Mitsudo K, Koike I, Koizumi T, Oguri S, Kioi M, Omura M, Tohnai I, Inoue T. Radiation therapy with concurrent retrograde superselective intra-arterial chemotherapy for gingival carcinoma. Strahlenther Onkol. 2014;190:181-5.

2. Hayashi Y, Osawa K, Nakakaji R, Minamiyama S, Ohashi N, Ohya T, lida M, Iwai T, Ozawa T, Oguri S, Koizumi T, Hirota M, Kioi M, Hata M, Mitsudo K. Prognostic factors and treatment outcomes of advanced maxillary gingival squamous cell carcinoma treated by intra-arterial infusion chemotherapy concurrent with radiotherapy. Head Neck. 2019;41:1777-84.

3. Shingaki S, Nomura T, Takada M, Kobayashi T, Suzuki I, Nakajima T. Squamous cell carcinomas of the mandibular alveolus: analysis of prognostic factors. Oncology. 2002;62:17-24.

4. Lubek J, El-Hakim M, Salama AR, Liu X, Ord RA. Gingival carcinoma: retrospective analysis of 72 patients and indications for elective neck dissection. British Journal of Oral and maxillofacial surgery. Br J Oral Maxillofac Surg. 2011;49:182-5.

5. Torre LA, Bray F, Siegel RL, Ferlay J, Lortet-Tieulent J, Jemal A. CA Cancer J Clin. 2015;65:87-108.

6. Fu X, Chen S, Chen W, Yang Z, Song M, Li H, Zhang H, Yao F, Su X, Liu T, Yang AK. Clinical analysis of second primary gingival squamous cell carcinoma after radiotherapy. Oral Oncol. 2018;84:20-4.

7. Hiratsuka H, Kohama G, Miyagawa A, Yamamoto E, Odani M, Tsutsumida R, Takahasi S, Tamaguchi A, Suzuki D. Treatment results for squamous cell carcinoma of the lower alveolar ridge (in Japanese). J Jpn Stomatol Soc. 1987;36:512-26.

8. Mitsudo K, Hayashi Y, Minamiyama S, Ohashi N, lida M, Iwai T, Oguri S, Koizumi T, Kioi M, Hirota M, Koike I, Hata M, Tohnai I. Chemoradiotherapy using retrograde superselective intra-arterial infusion for tongue cancer: analysis of therapeutic results in 118 cases. Oral Oncol. 2018;79:71-7.

9. NCCN Clinical practice guidelines in oncology. Head and neck cancer 2016. URL: https://oralcancerfoundation.org/wp-content/uploads/2016/09/headand-neck.pdf. Accessed 25 Aug 2019.

10. Kobayashi W, Teh BG, Sakaki H, Sato H, Kimura H, Kakehata S, Nagahata M. Superselective intra-arterial chemoradiotherapy with docetaxel-nedaplatin for advanced oral cancer. Oral Oncol. 2010;46:860-3.

11. Lozza L, Cerrotta A, Gardani G, De Marie M, Di Russo A, Kenda R, Tana S, Valvo F, Zucali R. Analysis of risk factors for mandibular bone radionecrosis after exclusive low dose-rate brachytherapy for oral cancer. Radiother Oncol. 1997:44:143-7.

12. Response Evaluation Criteria in Solid Tumors (RECIST ver. 1.1), URL: https:// recist.eortc.org/recist-1-1-2/. Accessed 25 Aug 2019.

13. The Common Terminology Criteria for Adverse Events (CTCAE) v4.03. URL: https://ctep.cancer.gov/protocolDevelopment/electronic_applications/ctc. htm\#ctc_40. Accessed 25 Aug 2019.

14. Shah JP, Gil Z. Current concepts in management of oral cancer--surgery. Oral Oncol. 2009;45:394-401.

15. Lin CY, Wang HM, Kang CJ, Lee LY, Huang SF, Fan KH, Chen EY, Chen IH, Liao CT, Chang JT. Primary tumor site as a predictor of treatment outcome for definitive radiotherapy of advanced-stage oral cavity cancers. Int J Radiat Oncol Biol Phys. 2010;15(78):1011-9.

16. Muñoz Guerra MF, Naval Gías L, Campo FR, Pérez JS. Marginal and segmental mandibulectomy in patients with oral cancer: a statistical analysis of 106 cases. J Oral Maxillofac Surg. 2003;61:1289-96. 
17. El Fattah H, Zaghloul A, Pedemonte E, Escuin T. Pre-prosthetic surgica alterations in maxillectomy to enhance the prosthetic prognoses as part of rehabilitation of oral cancer patient. Med Oral Patol Oral Cir Bucal. 2012;17: e262-70.

18. Schliephake $\mathrm{H}$, Jamil MU. Prospective evaluation of quality of life after oncologic surgery for oral cancer. Int J Oral Maxillofac Surg. 2002;31:427-33.

19. Nassiri AM, Campbell BR, Mannion K, Sinard RJ, Netterville JL, Rohde SL. Survival outcomes in T4aNOMO mandibular gingival squamous cell carcinoma treated with surgery alone. Otolaryngol Head Neck Surg. 2019; 160:870-5.

20. Lang K, Akbaba S, Held T, Kargus S, Horn D, Bougatf N, Bernhardt D, Freier K, Rieken S, Debus J, Adeberg S. Definitive radiotherapy vs. postoperative radiotherapy for lower gingival carcinomas of the mandible : a single-center report about outcome and toxicity. Strahlenther Onkol. 2019;195(9):819-29.

21. Kobayashi W, Teh BG, Kimura H, Kakehata S, Kawaquchi H, Takai Y.

Comparison of osteoradionecrosis of the jaw after superselective intraarterial chemoradiotherapy versus conventional concurrent chemoradiotherapy of oral cancer. J Oral Maxillofac Surg. 2015;73:994-1002.

22. Ujpál M, Barabás J, Kovalszky I, Szabó G, Németh Z, Gábris K, Suba Z. A preliminary comparative study of the prognostic implications of type 2 diabetes mellitus for patients with primary gingival carcinoma treated with surgery and radiation therapy. J Oral Maxillofac Surg. 2007;65:452-6.

\section{Publisher's Note}

Springer Nature remains neutral with regard to jurisdictional claims in published maps and institutional affiliations.

Ready to submit your research? Choose BMC and benefit from:

- fast, convenient online submission

- thorough peer review by experienced researchers in your field

- rapid publication on acceptance

- support for research data, including large and complex data types

- gold Open Access which fosters wider collaboration and increased citations

- maximum visibility for your research: over $100 \mathrm{M}$ website views per year

At $\mathrm{BMC}$, research is always in progress.

Learn more biomedcentral.com/submissions 